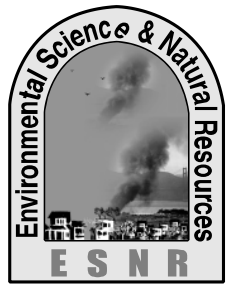

\title{
Temperature Anomaly and Severe Cyclone Events in the Southern Coastal Regions of Bangladesh
}

\author{
M. A. Farukh* and M. A. Baten
}

Department of Environmental Science, Faculty of Agriculture

Bangladesh Agricultural University, Mymensingh-2202

*Corresponding author: maf_bau@yahoo.com

\begin{abstract}
Bangladesh is a disaster prone country where cyclone occurs more frequently in recent decades. In this study, 52 cyclone events observed mainly in the southern coastal regions of Bangladesh from 1960 to 2010 were considered. Extreme weather data were obtained from Disaster Preparedness Centre, AIT and Bangladesh Bureau of Statistics. NCEP-NCAR reanalysis data were used to find out the distribution of temperature anomaly over Bangladesh and Bay of Bengal (BB). Skew-T Log-P analysis is done to assess vertical instability of upper atmosphere. The results suggest the prevalence of severe cyclones like category 3 to 5 is mostly from September to December, which are increasing since last two decades. The Skew-T Log-P analysis derived instability indices like CAPE, CIN, KI, LI, and SHOW are very useful to assess extreme weather phenomena. But the strongest signal behind severe cyclone formation over BB is the formation of relatively cooler zone (strong negative anomaly) near to surface level, whereas at the same time the upper atmosphere was dominated by the development of relatively warmer zone (strong positive anomaly).
\end{abstract}

Key words: Climatology, Extreme weather, Severe cyclone, Temperature anomaly, Vertical instability

\section{Introduction}

Cyclone occurs more frequently in Bangladesh due to its geographical location which located in the northern part of the Bay of Bengal (BB) as well as North Indian Ocean (NIO). The country has experiences about $0.93 \%$ of the world's total tropical cyclones (Ali, 1999). Depending upon the pressure distribution in the atmospheric winds and its mode of circulation in the BB, Bangladesh experiences all types of cyclones like cyclonic storm, severe cyclonic storm, very severe cyclonic storm and super cyclonic storm. Surface warm moist southerly wind from the BB and warm dry westerly wind from Indian territory toward Bangladesh is the main characteristic feature in the pre-monsoon season that could lead to form strong horizontal moisture gradient. Tropical cyclones and tornadoes have serious and adverse impacts on the economy, as well as on the whole environment. Every year severe convective storms in Bangladesh cause the highest death toll in the world, where 179 deaths per year caused only from cyclones and tornadoes in Bangladesh from 1967 to 1996 (Ono, 2001). Usually there prevails strong cool dry northwesterly wind that extends to westerly jet over the north-eastern part of Indian subcontinent in the mid and upper troposphere. In between dry and moist region, strong moisture gradient, temperature and pressure difference, significant vertical wind shear and temperature inversion over moist side produce great potential instability which develops favorable conditions for frequent and intense convective activities in Bangladesh and north-east India (Weston, 1972; Prasad, 2006; Yamane and Hayashi, 2006; Yamane et al., 2010a).

Nevertheless, in last few decades a number of studies have been done on this devastating event. Peterson and Mehta (1981) and Yamane et al. (2010a) described the central part of Bangladesh as a potential region of convective storm development. The dynamic and thermodynamic aspects of the initiation of severe convective storms were investigated by Yamane et al. (2010b); Murata et al. (2011); and Lohar and Pal (1995). The propagation and modes of organization of mesoscale convective systems were studied by Dalal et al. (2012), and lower, mid and upper tropospheric features for initiation of nor'westers ('kalboishakhi' in Bengali) were investigated by Ghosh et al. (2008). Mukhopadhyay et al. (2009) explained the formation mechanism of severe local convective storms with interaction of large and mesoscale environment over West Bengal, India. The synoptic features and environmental conditions of the tornado outbreak in the east-central region of Bangladesh were reported by Akter and Ishikawa (2014). However, the vertical temperature anomaly induced severe cyclone events are not yet well studied in Bangladesh. Therefore, this study reveals the upper atmospheric temperature variability related to 52 cyclone events from 1960 to 2010 observed in the southern part of Bangladesh mainly over BB.

\section{Data and Methodology}

The BB is situated to the south, and central part is one of the largest deltas of the world, the GangesBrahmaputra-Meghna River delta, that belongs to Bangladesh territory. We investigated 52 severe cyclone events mainly observed in the southern coastal regions of Bangladesh from 1960 to 2010. The data of cyclone occurrence, tidal surge, wind speed, and so on were collected from Disaster Preparedness Centre, AIT, Bangkok and Bangladesh Bureau of Statistics (BBS, 2011), Bangladesh. Study of extreme weather event like severe cyclone in Bangladesh is difficult due to its localized characteristics and lack of observation 
technologies. Existing observations do not describe the event precisely which compelled us to use reanalysis data. Therefore, the data source of composite mapping for air temperature used in this study is taken from the National Centers for Environmental Prediction (NCEP)-National Center for Atmosphere Research (NCAR) reanalysis project (Kalnay et al., 1996). This data source ensures a good quality of atmospheric data with a grid of $2.5^{\circ}$ resolution. The analysis region with the synoptic features are discussed over a domain encompassing $78^{\circ} \mathrm{E}-106^{\circ} \mathrm{E}$ and $10^{\circ} \mathrm{N}-34^{\circ} \mathrm{N}$ (Fig. 4$5)$. This study deals with only the vertical instability and effect of temperatures on cyclone events in Bangladesh and, therefore, composite air temperature anomaly maps for different levels of atmosphere is constructed based on air temperature conditions of 52 cyclone occurring days.

To compare with upper air temperature anomaly conditions a test case was chosen on the date of AILA (category 1 tropical cyclone, 25 May 2009) occurrence in Bangladesh. To examine environmental conditions, several stability indices are computed on the said date and a Skew-T Log-P diagram is derived from the radiosonde data archive of the College of Engineering, University of Wyoming (2015). The Skew-T Log-P is one of the most commonly used thermodynamic diagrams in weather analysis and forecasting using radiosonde parameters as well as to estimate the possibility of extreme weather development. Farukh et al. (2011a) used Skew-T Log-P analysis to describe extreme weather conditions to predict lightning occurrences. However, the computed convective parameters were $\mathrm{K}$ Index (KI), Showalter Stability Index (SHOW), Convective Available Potential Energy (CAPE, $\mathrm{Jkg}^{-1}$ ), Convective Inhibition (CIN, $\mathrm{Jkg}^{-1}$ ), and Lifted Index (LI). The physical meaning of the indices is well explained by Yamane et al. (2010b).

\section{Results and Discussion}

\section{Cyclone occurrence}

Neumann (1993) reported that about $6.5 \%$ of the world's total tropical cyclones originated in the NIO mainly along the BB and Arabian Sea, though the frequency of cyclones in the BB is about 5 to 6 times higher than that of in the Arabian Sea (IMD, 1979). However, the yearly and monthly distribution of cyclone occurrences in Bangladesh is shown in Fig. 1. The category of cyclones in Saffir-Simpson Hurricane Wind Scale (SSHWS; NOAA, 2015) is shown in Fig. 1 using numbers inside the rectangles and circles. Bangladesh experienced a total number of 52 cyclones in 50 years from 1960 to 2010 (Fig. 1). There are two main periods of cyclone occurrences in Bangladesh, one is form the beginning of March to the beginning of June $(65-186$ day numbers of the year) and another is form the end of September to the mid of December $(270$ - 352 day numbers of the year). Both of these two occurrence periods are shown in Fig. 1 using circles and rectangles, respectively. Appearance of two sporadic cyclones is shown in the figure using triangles (near to 240 day numbers of the year). The numbers inside the rectangles and circles implied the prevalence of severe cyclones mostly from September to December (category 3 to 5 cyclones). It is also noticed from this figure that 'September to December' cyclone occurrence rate was $62 \%$ from 1960 to 1990 , and $38 \%$ from 1991 to 2010, which indicates increasing rate of cyclone prevalence in recent decades. Chowdhury (2006) explained that the severe cyclones occurred in Bangladesh mostly during pre-monsoon (April - May) and postmonsoon (September - December) periods. But the frequency of circles gradually decreasing from 2000 to 2010 compared to the previous decade.

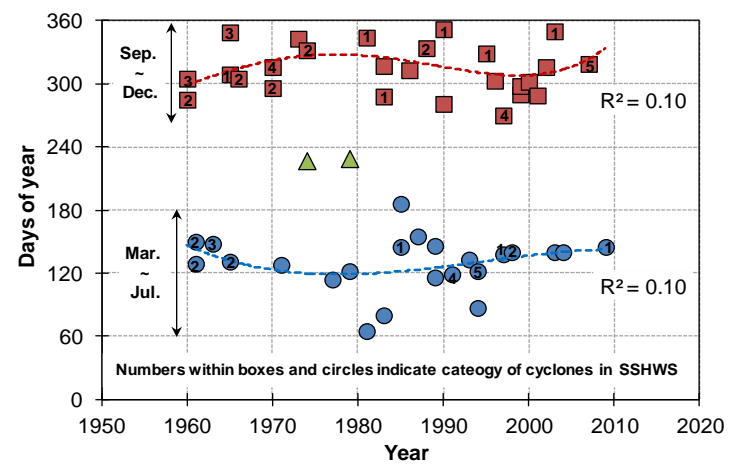

Fig. 1. Yearly and monthly distribution of cyclone occurrences in Bangladesh along with their category in Saffir-Simpson Hurricane Wind Scale (SSHWS)

\section{Extreme weather}

Fig. 2 shows the maximum tidal surge height (ft; in ' $\mathrm{x}$ ' axis), maximum wind speed $\left(\mathrm{k} \mathrm{hr}{ }^{-1}\right.$; in ' $\mathrm{yl}$ ' axis), and persons killed (number; in ' $y 2$ ' axis) due to the severe cyclone occurrences from 1960 to 2010. A strong relation of increment in between wind speed and tidal surge height is found from the figure. The highest death toll $(3,00,000)$ was recorded due to a severe cyclone event in November 1970 with the maximum tidal surge height of $33 \mathrm{ft}$. Some 280,000 cattle were lost along with about 99,000 boats. Another severe cyclone of April 1991 had a surge height in places of over $7 \mathrm{~m}$ and winds of up to $235 \mathrm{k} \mathrm{hr}^{-1}$. It killed an estimated 138,866 people and destroyed about 840,000 rural houses in 16 coastal districts.

To find out the probable extreme weather conditions responsible for severe cyclogenesis, a test case is chosen named severe cyclonic storm AILA that attacked Bangladesh on May 25, 2009. AILA developed over BB on May 23 and dissipated over sub-Himalayan West Bengal and Sikkim. The wind speed of AILA was 100 to $110 \mathrm{k} \mathrm{hr}^{-1}$ and the 
lowest estimated central pressure was about 968 $\mathrm{hPa}$ at the time of landfall (SDMC, 2009). As the monsoon rising up, environmental factors were favorable to develop an extreme weather condition that would trigger to intensify the cyclonic storm AILA. Therefore, a Skew-T Log-P analysis is used in Fig. 3 to assess the extreme weather conditions mainly focusing on upper air instability on 25 May 2009.

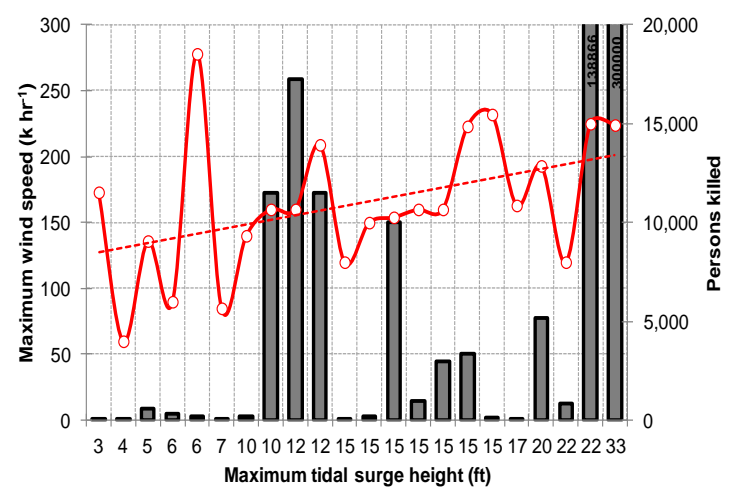

Fig. 2. Maximumtidal surge height, wind speed, and number of people killed due to severe cyclone occurrence in southern coastal regions of Bangladesh

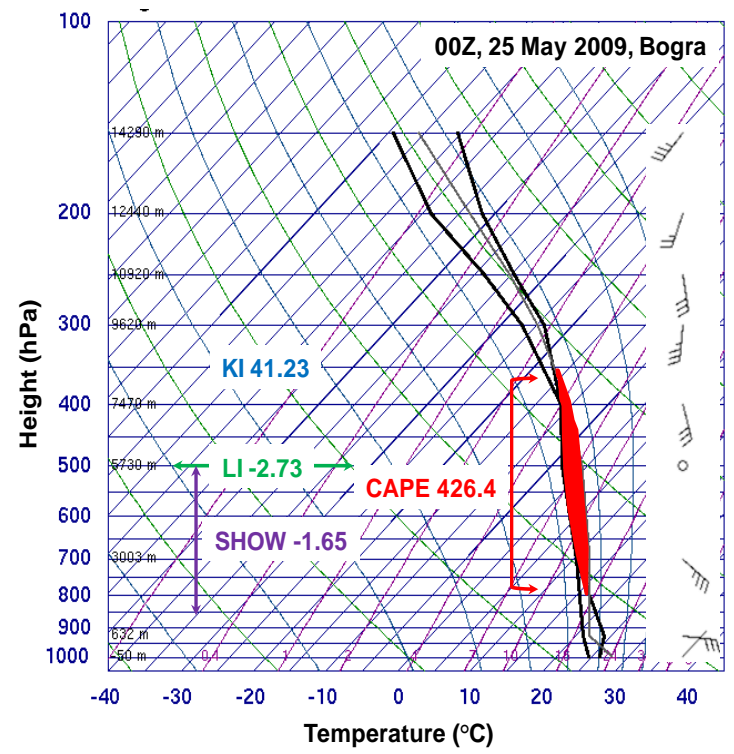

Fig. 3. Skew-T Log-P analysis at $00 \mathrm{Z}$ of Bogra station radiosonde data from University of Wyoming archive on May 25, 2009

In Fig. 3, 00Z Skew-T Log-P analysis for Bogra is shown along with vertical wind shear in the right side. Bogra station was selected due to its availability in the University of Wyoming archive. Though the values of radiosonde parameters were driven automatically along with the diagram but the computation for the instability indices were done again using the following equations to ensure the accuracy of instability indices.

$$
\begin{aligned}
& K I=\Delta T e_{850-500}+T d_{850}-D D_{700} \quad \ldots \ldots \ldots \ldots \ldots \ldots \ldots .(i) \\
& L I=T e_{500}-T p_{500} \quad \ldots \ldots \ldots \ldots \ldots \ldots \ldots \ldots \ldots \ldots \ldots \ldots \ldots \ldots \ldots \text { (ii) } \\
& \text { SHOW }=T e_{500}-T p_{850} \quad \ldots \ldots \ldots \ldots \ldots \ldots \ldots \ldots \ldots \ldots \text { (iii) } \\
& C A P E=\int_{Z f}^{Z n} g\left\{\frac{T p-T e}{T e}\right\} d z \\
& \text { CINS }=\int_{\approx \text { bottom }}^{\approx t o p} g\left\{\frac{T p-T e}{T e}\right\} d z
\end{aligned}
$$

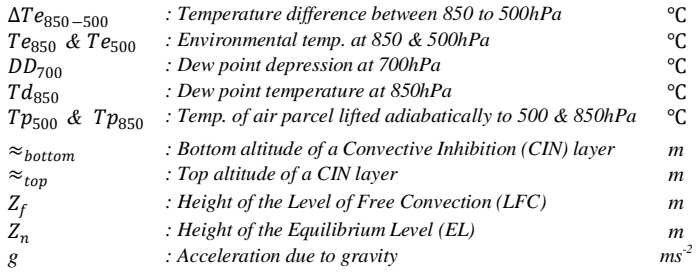

According to Fig. 3 high instability is identified where CAPE was $426.4 \mathrm{Jkg}^{-1}$ at $00 \mathrm{Z}$, where the instability zone ranged from 800 to $350 \mathrm{hPa}$. Though the plot suggests favorable atmospheric condition for convective initiation, Bogra station is about $400 \mathrm{~km}$ apart from the event site (e.g., Patuakhali, southern Bangladesh). But the KI (41.23) indicates instability from 850 to $500 \mathrm{hPa}$ considering dew point depression, LI (-2.73) and SHOW (-1.85) implies unstable upper atmosphere at $500 \mathrm{hPa}$ and $850 \sim 500 \mathrm{hPa}$, respectively. Westerly wind was prominent at surface and the wind turns upward. Strong south-easterly to southerly wind became prominent at upper atmosphere while the surface convergence influenced upward motion.

\section{Temperature anomaly and severe cyclone}

Fig. 4 (a), (b), and (c) shows the composite geographical distributions of surface air temperature anomalies compared with the climatology from 1981 to 2010 for the preceding day, on the day, and the succeeding days of cyclone occurrences, respectively. It is clearly shown from the Fig. 4 (a) that a strong positive surface air temperature anomaly zone over the eastern and south-eastern part of Bangladesh. This positive anomaly is prominent over the south-eastern hilly regions whereas, a strong negative anomaly zone is prominent over West Bengal of Indian territory, implies coexistence of strong positive and negative anomaly zones keeping the transition zone over the western border of Bangladesh. On the day of cyclone occurrences (Fig. 4 (b)), the strong negative anomaly zone from Indian territory expanded toward south-western territory of Bangladesh neutralizing the strong south-east positive anomaly zone. At the same time another strong negative anomaly zone is also evident over the southern part of Myanmar. On the succeeding day, both of the negative anomaly zones were fused together over southern Myanmar. The result suggests dominance of relatively cooler air temperatures in the southern zone near to surface level especially on the day of cyclone prevalence. 


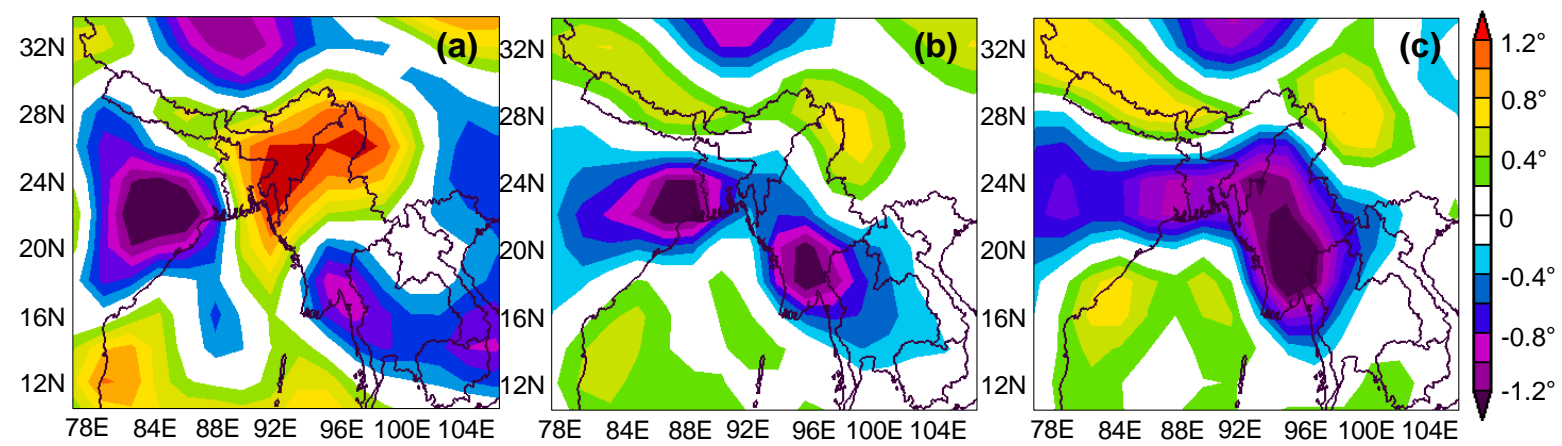

Fig. 4. The patterns of composite surface air temperature $\left({ }^{\circ} \mathrm{K}\right)$ anomaly compared with $1981-2010$ climatology; (a) preceding day of cyclones, (b) on the day of cyclones, and (c) succeeding day of cyclones

Fig. 5 (a), (b), (c), and (d) shows the composite air temperature anomalies at 850, 700, 500, and 300 $\mathrm{hPa}$ level of atmosphere on the days of cyclone occurrences, respectively. Fig. 5 (a) depicts a strong positive air temperature anomaly zone over the north-eastern part of Bangladesh at $850 \mathrm{hPa}$ level. The transition zone between positive and negative anomalies was existed over the BB keeping two negative zones over south-eastern India and southern Myanmar. But at around 3,000 $\mathrm{m}$ above $(700 \mathrm{hPa})$ from surface there was
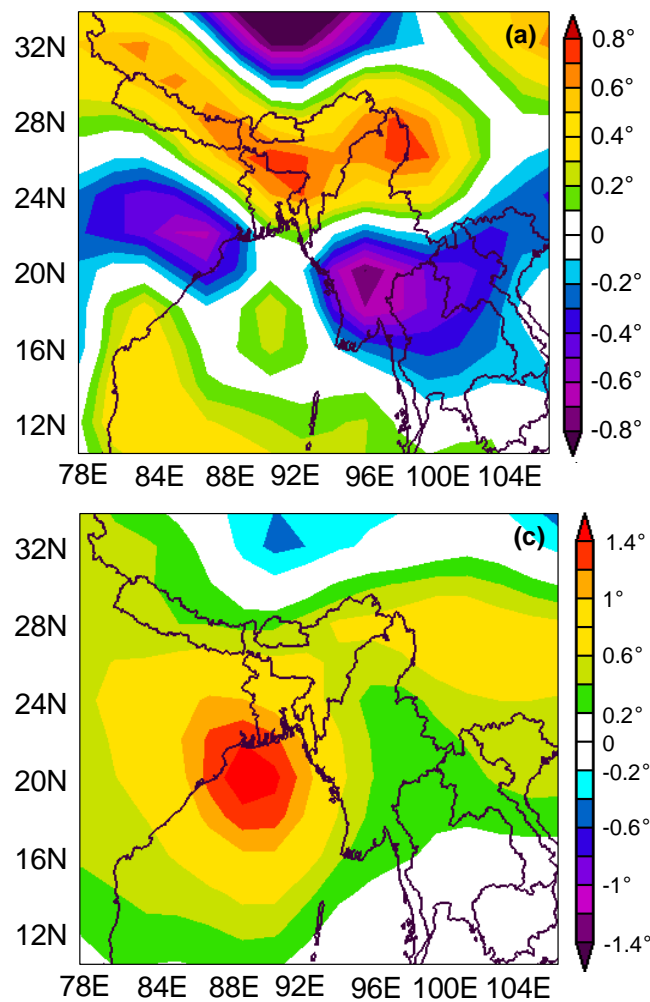

Fig. 5. The patterns of composite air temperature $\left({ }^{\circ} \mathrm{K}\right)$ anomaly on the day of cyclone occurrences compared with 1981-2010 climatology; (a) at $850 \mathrm{hPa}$, (b) at $700 \mathrm{hPa}$, (c) at $500 \mathrm{hPa}$, and (d) at $300 \mathrm{hPa}$

The temperature distribution at Fig. 5 (c) shows the anomaly of temperature at the most influential weather zone of upper atmosphere i.e., at $500 \mathrm{hPa}$ level. A strong positive zone encircled over the south-western part of Bangladesh and over BB indicates development of a warmer zone at around
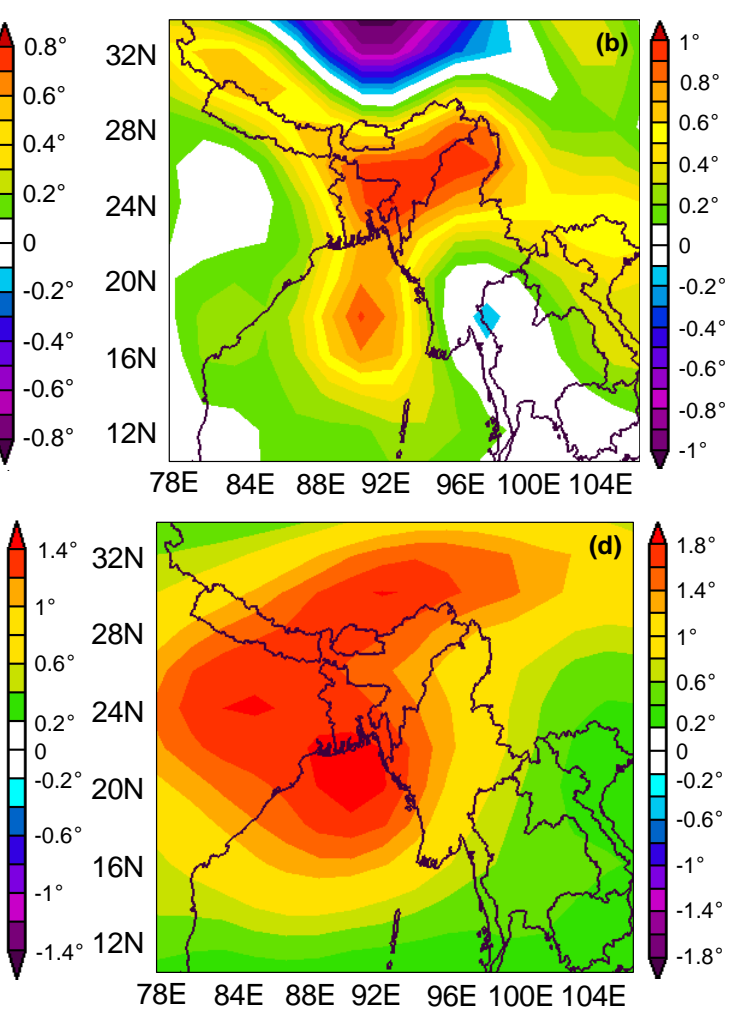

complete disappearance of negative anomaly zones. The positive zone expanded from north-east toward south-east and over BB. Thus, this warmer zone at relatively upper atmosphere could make unstable atmosphere through the thermal instability interacting with the surface layer. Yamane and Hayashi (2006) found high thermal instability and vertical wind shear in upper atmosphere over Bangladesh and the northeastern India during the pre-monsoon season.

$6,000 \mathrm{~m}(500 \mathrm{hPa})$ above from surface. The most dramatic phenomena is seen at $300 \mathrm{hPa}$ level ( 10,000 $\mathrm{m}$ above) where, a huge area is covered by positive anomaly extending from Tibet to NIO via eastern Indian territory (Fig. 5 (d)). Whole of the Bangladesh was dominated by positive 
anomaly values implies formation of a deep warmer zone over these regions. This larger warmer air mass at upper atmosphere could influence a lot to develop huge instability throughout the whole atmospheric column. The impact of such warmer air mass in relation to extreme lightning weather formation is well explained by Farukh et al. (2011b).

\section{Conclusions}

We investigated 52 cyclone events of Bangladesh from 1960 to 2010. Disaster Preparedness Centre (AIT), Bangladesh Bureau of Statistics, NCEPNCAR reanalysis data, and Skew-T Log-P analysis is done to assess the upper atmospheric temperature anomalies related to severe cyclone events in the southern part of Bangladesh mainly over BB. The results of this study describe the prevalence of severe cyclones (category 3 to 5) mostly from September to December. This severe cyclone occurrence rate is increasing in last two decades compared to preceding 3 decades. But it could be concluded from the extreme weather analysis using a test case of a severe cyclonic storm AILA that, Skew-T Log-P analysis derived instability indices

\section{References}

Akter, F. and Ishikawa, H. 2014.Synoptic features and environmental conditions of the tornado outbreak on March 22, 2013 at Brahmanbaria in the east-central region of Bangladesh, Nat. Hazards, DOI: 10.1007/s11069-014-1252-y.

Ali, A. 1999. Climate change impacts and adaptation assessment in Bangladesh, Climate Research, 12:109-116.

BBS (Bangladesh Bureau of Statistics), 2011. Statistics Division, Ministry of Planning, Statistical Year Book of Bangladesh - 2010, BBS, Dhaka, Bangladesh.

Chowdhury, M. H. 2006. Cyclone,Banglapedia: National Encyclopedia of Bangladesh, Asiatic Society of Bangladesh.

Dalal, S.; Lohar, D.; Sarkar, S.; Sadhukhan, I. and Debnath, G. C. 2012. Organizational modes of squall-type mesoscale convective systems during premonsoon season over eastern India, Atmos. Res, 106:120-138.

Farukh, M. A.; Hayasaka, H. and Kimura, K. 2011 a. Recent Anomalous Lightning Occurrences in Alaska- the Case of June 2005-, Journal of Disaster Research, 6(3):321-330.

Farukh, M. A.; Hayasaka, H. and Kimura, K. 2011b. Characterization of Lightning Occurrence in Alaska Using Various Weather Indices for Lightning Forecasting, Journal of Disaster Research, 6(3):343-355.

Ghosh, A.; Lohar, D. and Das, J. 2008. Initiation of Nor' wester in relation to mid-upper and lowlevel water vapor patterns on METEOSAT-5 images, Atmos. Res, 87:116-135. like CAPE, CIN, KI, LI, and SHOW could give a reasonable account of scenarios to assess extreme weather phenomena, as well as a forecasting system of severe cyclone formation could also be built based on these upper atmospheric stability indices. The climatological anomaly of air temperatures at different levels of atmosphere showed the dominance of relatively cooler air temperatures in the southern zone near to surface level especially on the day of cyclone prevalence for Bangladesh. But just a few kilometer above, the whole vertical atmospheric column started to increase its temperature especially from 850 to 300 $\mathrm{hPa}$ levels. These warmer zones at relatively upper atmosphere could make unstable atmosphere through the thermal instability interacting with the surface layer. Finally, the whole of Bangladesh was dominated by positive anomaly values up to 300 $\mathrm{hPa}$ level implies formation of a deep warmer zone over this region. The larger warmer air mass at upper atmosphere creates profound influenceto develop huge instability throughout the whole atmospheric column that could lead to extreme weather phenomenon like severe cyclone.

IMD (India Meteorological Department), 1979. Tracks of storms and depressions in the Bay of Bengal and the Arabian Sea, IMD, New Delhi, India. pp. 1877-1970.

Kalnay, E.; Kanamitsu, M.; Kistler, R.; Collins, W.; Deaven, D.; Gandin, L.; Iredell, M.; Saha, S.; White, G.; Woollen, J.; Zhu, Y.; Chelliah, M.; Ebisuzaki, W.; Higgins, W.; Janowiak, J.; Mo, K. C.; Ropelewski, C.; Wang, J.; Leetma, A.; Reynolds, R.; Jeene, R. and Joseph, D. 1996. The NCEP/NCAR 40-year reanalysis project, Bulletin of the American Meteorological Society, 77: 437-471.

Lohar, D. and Pal, B. 1995. The effect of irrigation on pre-monsoon season precipitation over south West Bengal, India. J. Clim., 8(1995): 2567-2570.

Mukhopadhyay, P.; Mahakur, M. and Singh, H. A. K. 2009. The interaction of large scale and mesoscale environment leading to formation of intense thunderstorms over Kolkata Part I: Doppler radar and satellite observations, $J$. Earth Syst. Sci., 118(5):441-466.

Murata, F.; Terao, T.; Kiguchi, M.; Fukushima, A.; Takahashi, K.; Hayashi, T.; Arjumand, H.; Bhuiyan, M. S. H. and Choudhury, S. A. 2011. Daytime thermodynamic and airflow structures over northeast Bangladesh during the premonsoon season: a case study on 25 April 2010. J. Meteorol. Soc. Jpn., 89A:167-179.

Neumann, C. J. 1993. Global overview: Chapter 1, Global guide to tropical cyclone forecasting. World Meteorological Organization, Geneva. 
NOAA (National Oceanic and Atmospheric Administration), 2015. National Weather Service, National centers for environmental prediction, http://www.nhc.noaa.gov/about sshws.php (last accessed on 4 August 2015)

Ono, Y. 2001. Design and adoption of household tornado shelters to mitigate the tornado hazard in Bangladesh. PhD Dissertation, Kent State University.

Peterson, R. E. and Mehta, K. C. 1981. Climatology of tornadoes of India and Bangladesh, Arch. Meteorol. Geophys. Bioklimatol. Ser. B., 29:345-356.

Prasad, K. 2006. Environmental and synoptic conditions associated with no'westers and tornadoes in Bangladesh - an appraisal based on numerical weather prediction (NWP) guidance products. $14^{\text {th }}$ report of SAARC Meteorological Research Center, Dhaka, Bangladesh

SDMC (SAARC Disaster Management Centre), 2009. South Asia Disaster Report 2008, SDMC, New Delhi, India.
University of Wyoming. Department of Atmospheric Science, College of Engineering. http://weather.uwyo.edu/cgibin/sounding?regio n=seasia\&TYPE=TEXT\%3ALIST \&YEAR=2 $013 \&$ MONTH=03\&FROM=2200\&TO=2200 $\&$ STNM=41923 (last accessed on 6 July 2015)

Weston, K. J. 1972. The dry-line of northern India and its role in cumulonimbus convection. $Q . J$. R. Meteorol. Soc., 98(417):519-531.

Yamane, Y. and Hayashi, T. 2006. Evaluation of environmental conditions for the formation of severe local storms across the Indian subcontinent, Geophys. Res. Lett., 33:L17806.

Yamane, Y.; Hayashi, T.; Dewan, A. M. and Akter, F. 2010a. Severe local convective storms in Bangladesh: part 1, Climatol. Atmos. Res., 95:400-406.

Yamane, Y.; Hayashi, T.; Dewan, A. M. and Akter, F. 2010b. Severe local convective storms in Bangladesh: part 2, Environmental conditions. Atmos. Res., 95:407-418. 